Article

\title{
Functional Characterization and Diversity of Ammonia- Oxidizing Microorganisms in Streams South of the Dabie Mountains, China
}

\author{
Amjed Ginawi ${ }^{1,2}$, Wang Lixiao ${ }^{1}$, Huading Wang ${ }^{1}$, Bingbing Yu ${ }^{1}$, Yunjun Yan ${ }^{1, *}$ \\ 1Key Lab of Molecular Biophysics of Ministry of Education, College of Life Science and Technology, Huazhong \\ University of Science and Technology, 1037 Luoyu Road, Wuhan, 430074, China. \\ 2Faculty of Marine Science and Fisheries, Red Sea University, Port Sudan, Sudan. \\ 1 Amjed Ginawi: amjedginawi@rsu.edu.sd \\ 2 Wang Lixiao: zdwanglixiao@163.com \\ 3 Huading Wang: 1712661198@qq.com \\ 4 Bingbing Yu: 1265255681@qq.com \\ *Corresponding Author: \\ 5 Yunjun Yan, PhD. \\ College of Life Science and Technology \\ Huazhong University of Science and Technology \\ Address: 1037 Luoyu Rd, Hongshan District, Wuhan City, Hubei Province 430074, P. R, China \\ Telephone number: 86-27-87792213 \\ E-mail: yanyunjun@hust.edu.cn
}

\begin{abstract}
Ammonia-oxidizing microorganism communities are abundant and functionally efficacious in nitrification. However, ammonia-oxidizing archaea (AOA) and ammonia-oxidizing bacteria (AOB) groups complicate this process in subtropical streams. This study investigates the abundance of ammonia-oxidizing communities south of the Dabie Mountains, China, using quantitative polymerase chain reaction (qPCR). Clone libraries were utilized to analyze the abundance and microbial structures of $\mathrm{AOA}$ and $\mathrm{AOB}$ in sediments. Such analysis may provide strong evidence reflecting the links within the environment. The results show that $\mathrm{AOB}$ had a lower abundance of copies of the ammonia-oxidizing gene $(a m o A)$ than $\mathrm{AOA}$. Interestingly, the $\mathrm{AOA}$ and $\mathrm{AOB}$ community compositions were correlated with ecological characteristics. The dissolved oxygen (DO) and oxidation-reduction potential (ORP) had significant positive correlations, whereas the phosphorus within the structure had a negative correlation with the abundance of both groups. Our study shows that it might adopt some species related to Nitrosotalea clusters that can resist comparably higher $\mathrm{pH}$ (toward $\mathrm{pH}$ 6.5). Together, these results imply that the physiological adaptation of microbial guilds to environmental pressures in ammonia-oxidizing archaea might allow them to have a more substantial function of ammonia-oxidizing communities in natural habitats.
\end{abstract}

Keywords: ammonia oxidation; ammonia-oxidizing archaea; ammonia-oxidizing bacteria; gene function stream; nitrification 


\section{Introduction}

The nitrification model has changed with the reduction of ammonia-oxidizing archaea (AOA) in the last 15 years, and ammonia-oxidizing bacteria (AOB) were observed as a single group interceding in ammonia oxidation [1]. In reality, studies of malodor in stream sediment by the 16S rRNA clone library [1] and the determination of ammonia-oxidizing ( $а m o A)$ genes [2] showed that AOA amoA gene copies were based on higher numbers compared with AOB in many soil and stream environments [3]. The ammonia-oxidizing gene is an effective indicator of the limiting steps in nitrification and a possible community indicator of mineral content [4]. As a gene function target, amoA is more useful than the $16 \mathrm{~S}$ rRNA scheme for investigating AOA and AOB population structures [5].

The typical optimum $\mathrm{pH}$ for nitrification is 7.8 [6,7]. However, nitrification could dispose of excess ammonium nitrogen and protect the river from eutrophication [8]. Therefore, the physiochemical characteristics may affect the population of microbes to participate in several processes such as nitrogen cycling $[9,10]$. Compared to $\mathrm{AOA}, \mathrm{AOB}$ is very sensitive to higher $\mathrm{pH}$ values $[11,12]$ and less dominant $[13,14]$.

Reducing ammonia in the environment is one of the key functions of $\mathrm{AOA}$ and $\mathrm{AOB}$, and it is attained by nitrification. AOA supports nitrification in different habitats, separate studies of $\mathrm{AOB}$ and AOA functions in ammonia oxidation have attracted significant attention and many researchers [15]. The ammonia-oxidation cycle in environmental studies is distinctive compared to microbiological studies [16]. The microbial communities are active in nitrogen fixation and strongly participate in the process of turnover of river cycling substances. Human influence can significantly increase the eutrophication in aquatic ecosystems $[17,18]$, but the density of ammonium in freshwater has risen as a consequence of increased farmland use of ammonium, causing environmental hazards [19,20] and affecting the nitrification cycle in microbial ecology.

The high concentrations of ammonia in river streams are toxic to fish and other aquatic living organisms. The rivers are characterized by rich geographic and physicochemical ranges. Therefore, they represent a good environment for the existence of a diverse microbial ecosystem [21]. Luotian River, also known as Yishui, which is $87 \mathrm{~km}$ long and $80-220 \mathrm{~m}$ wide, converges into the Ba River and then the Yangtze River (Figure 1).

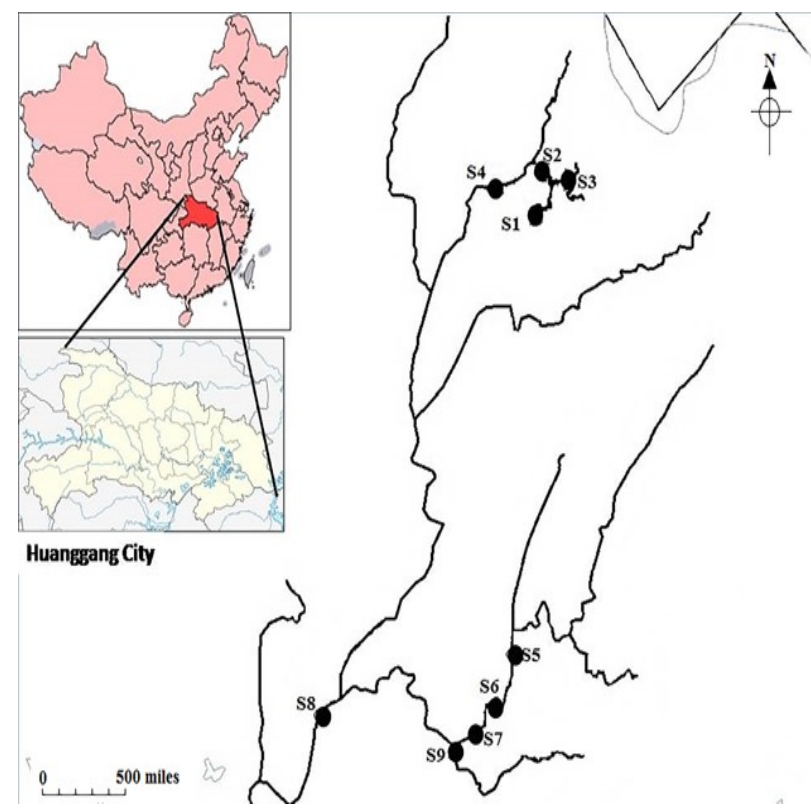

Figure 1. A schematic diagram showing the locations of the sampling sites in the Luotian River, upstream (S1, S2, and S3), in the human influences (S4, S5, S6, and S7), discharge of waste treatment plant (S9) and in the downstream (S8). 
Taking DNA samples from the river environment is a new approach for in situ studies of microbial diversity. Moreover, the development of technical polymerase chain reaction (PCR) promotes the process of DNA amplification [22], even though many microbes are not smoothly achievable as cultured strains in the research laboratory, which would enable proper identification and description of species.

The aims of this study are (1) to determine the abundance and diversity of AOA and AOB in the stream ecosystem by identifying specific functional gene markers, (2) to extend our knowledge of new AOA species in freshwater sediments with various ammonium conditions, (3) to implement a broad survey of the supposed ammonia-oxidizing genes with high physicochemical value in various seasons in Hubei, China, and (4) to find possible links between environmental stream parameters and the dynamics of ammonia oxidizers.

\section{Results2.1. Archaeal and Bacterial amoA-Based Community Structures}

$\mathrm{AOA}$ and $\mathrm{AOB}$ amo $A$ genes were sequenced partially in nine sites. A total of 109 archaeal amo $A$ clone libraries were randomly selected, and 54 archaeal amo $A$ sequences were analyzed. As a result, 34 operational taxonomic units (OTUs) were recovered based on one amino acid residue cutoff (Figure 2, Supplementary Table S3). In addition, 83 bacterial amoA clone libraries were prepared, and a total of 61 bacterial amo $A$ sequences were analyzed. Out of these, three OTUs were recovered, based on one amino acid residue cutoff (Supplementary Figure S1, Table S3). BLASTn analysis identified that most sequences were closely associated with uncultured bacteria of $a m o A$ genes. For the most similar GenBank sequences based on the BLASTn results, ammonia monooxygenase genes were inserted into the dataset. Sequence alignment was implemented, and the phylogenetic tree is represented in Figure 2 and Supplementary Figure S1. A neighbor-joining tree was designed using amo $A$ gene sequences and sequences related to those accessed from GenBank. Most of the sequences were Nitrososphaera (there were four AOA clusters (I.1, I.2, I.3, and I.4), and one AOB cluster belonged to genus Nitrosomonas (Supplementary Figure S1)). The coverage (C) ranged from $14 \%$ to $80 \%$ in AOA and $85 \%$ to $88 \%$ in AOB (Supplementary Table S3).

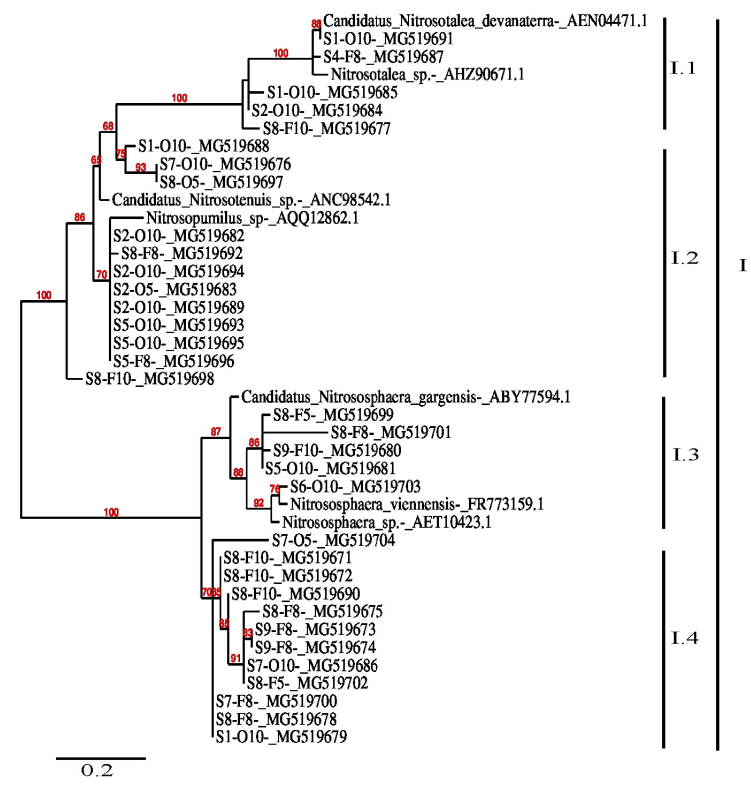

Figure 2. The phylogenetic tree the neighbor-joining showing the phylogenetic relationships of ammonia oxidizing archaea (AOA) amoA gene sequences. Bootstrap support values (1000 replicates) are shown. The scale bar represents 0.2; evolutionary analyses were implemented in MEGA 7.

\subsection{Relationship of Bacterial Composition and Environmental Variables}


The relationship between ammonia oxidization group structures was observed in various sampling sites by principal component analysis (PCA) using PAST v.3.15 software [23], based on the ammonia oxidization group sequences (Figure 3).

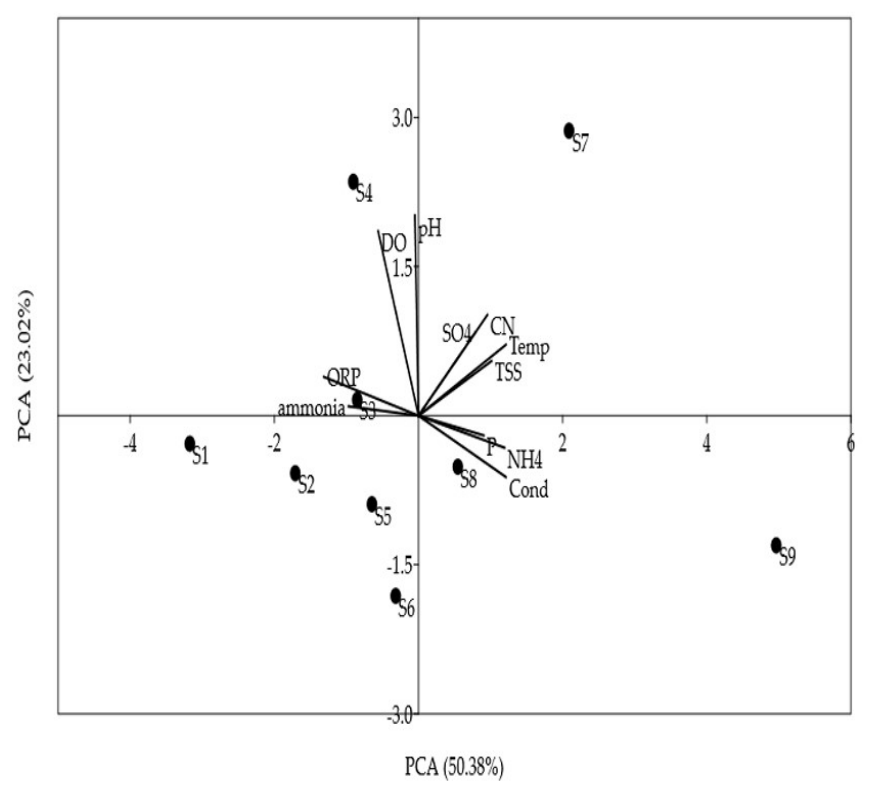

Figure 3. Principal component analysis (PCA) ordination plots for the environmental indicator and ammonia oxidizing groups in Luotian River - China and environmental variables axes are represented by the lengths of arrows (circles: sampling sits arrows, environmental variables).

The AOA and AOB communities from upstream were positively related to oxidation-reduction potential (ORP), $\mathrm{pH}$, and dissolved oxygen, and negatively associated with phosphorus, which showed few dynamics in our investigation sites. The AOB community structure was correlated with conductivity in several ways. Canonical correspondence analysis (CCA) was used to describe the key environmental factors, showing the functional genes in the $a m o A$ groups. We then used CCA to analyze the multivariate relationships between the abundance of ammonia oxidization genes (AOA and $\mathrm{AOB}$ ) and the environmental parameters (Figure 4a). All correlation analyses were applied to evaluate the significant number of relations ( $p$-values). Our results show that ORP and phosphorus had important influences on $\mathrm{AOA}$ and $\mathrm{AOB}$ communities in all sediments. Furthermore, the overall composition of the AOB communities was negatively correlated with phosphorus and conductivity (Figure 4b). Similarly, $\mathrm{pH}$ was positively or negatively correlated with the overall composition of the AOB (CCA; Figure 4b).

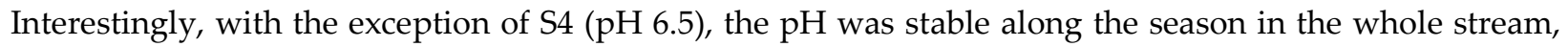
representing the significant explanatory power of our study. The order of the dominant factors corresponding to the levels of impact on the ammonia monooxygenase communities was ORP, dissolved oxygen (DO), conductivity, phosphorus, and $\mathrm{pH}$. 
(a)

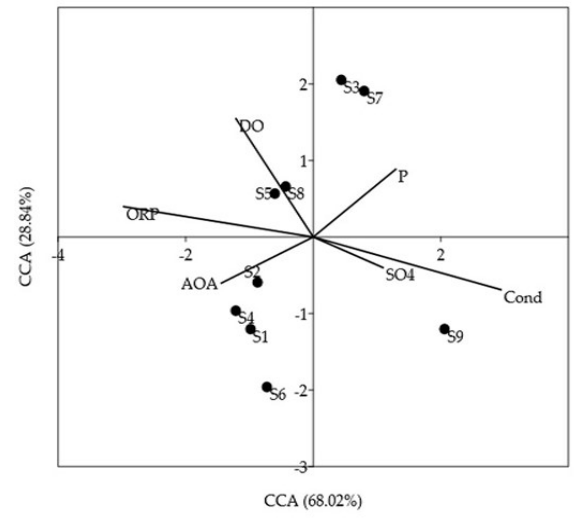

(b)

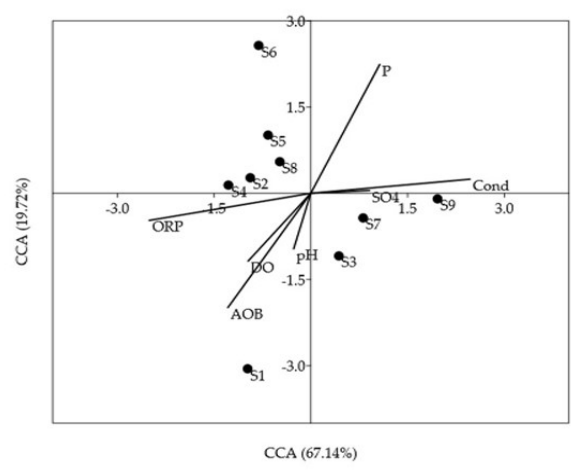

Figure 4. The relationship between (a) the ammonia oxidizing archaea AOA and (b) ammonia oxidizing bacteria $\mathrm{AOB}$, amoA community compositions in Luotian River, China and environmental parameters. Correlations between canonical correspondence analysis (CCA) and environmental variables axes are represented by the lengths of arrows (circles: sampling sits arrows, environmental variables). Only analyses that showed significant Spearman corrected $p$-values are included.

\subsection{Relative Abundance of Dominant Bacterial Community Structure South of the Dabie Mountains}

The 84 positive clone sediments of 16S rRNA genes were collected from the sampling station. Out of the clones, 3\%-14\% (Cyanobacteria phylum) were excluded from our analysis since we only focused on heterotrophic bacteria. The relative abundance of the bacterial composition community clones is shown in Figure 5. It was observed that the Betaproteobacteria appeared at each station during the whole study. However, the Bacteroidetes did not appear in May (abundance $>1 \%$ ); May and August clones were the most diverse, featuring Deinococcus-Thermus, Actinobacteria, Acidobacteria, Proteobacteria (alpha, beta, and gamma), Bacteroidetes, Chloroflexi, Firmicutes, Armatimonadetes, and Planctomycetes (division OP10), while the Deltaproteobacteria, Latescibacteria, and Planctomycetes groups only appeared in October. 


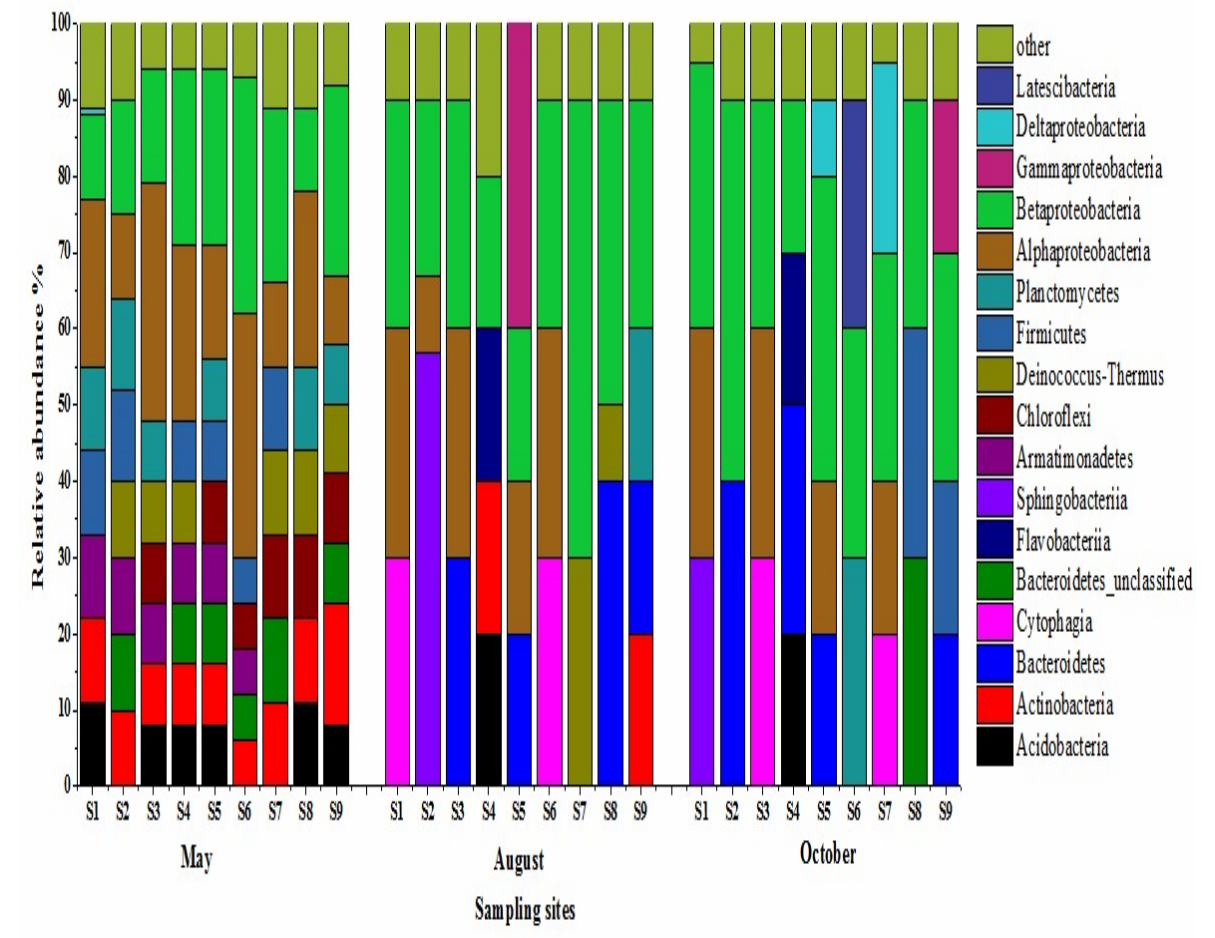

Figure 5. Relative abundance of the amplified 16S rRNA gene clone library with different divisions in the bacteria community clone during May, August, and October 2017. The cloned sequences were compared with the most closely related sequences obtained from the database (RDP). The clones attached with Deinococcus-Thermus, Actinobacteria, Acidobacteria, Proteobacteria (alpha, Beta and Gamma), Bacteroidetes, Chloroflexi, Firmicutes, Armatimonadetes, and Planctomycetes division OP10 are included in 'Others'.

\subsection{Functional Gene Abundance of Bacteria ( $A O A$ and $A O B)$ in Streams}

Nine stations along the streams were selected to investigate the functional genes (amo $A$ genes) of $\mathrm{AOA}$ and $\mathrm{AOB}$. Our results show that there were no significant variations in total microorganisms as evaluated by 16S rRNA (Supplementary Table S2), and concentrations of functional (AOA and AOB) genes were found irrespective of sampling site.

The higher numbers of gene copies of AOA and AOB (Figure 6) in the samples from S1 and S8 were $5.28 \times 10^{8}$ and $5.1 \times 10^{8}$ gene copies (g.soil ${ }^{-1}$ ), respectively. In most sampling sites, the higher numbers of gene copies were presented by the $16 \mathrm{~S}$ rRNA group when compared to the AOA group (Supplementary Table S2). Among all upstream stations, AOA was higher than AOB, while sites S4 and S5 downstream had higher AOB than AOA. 


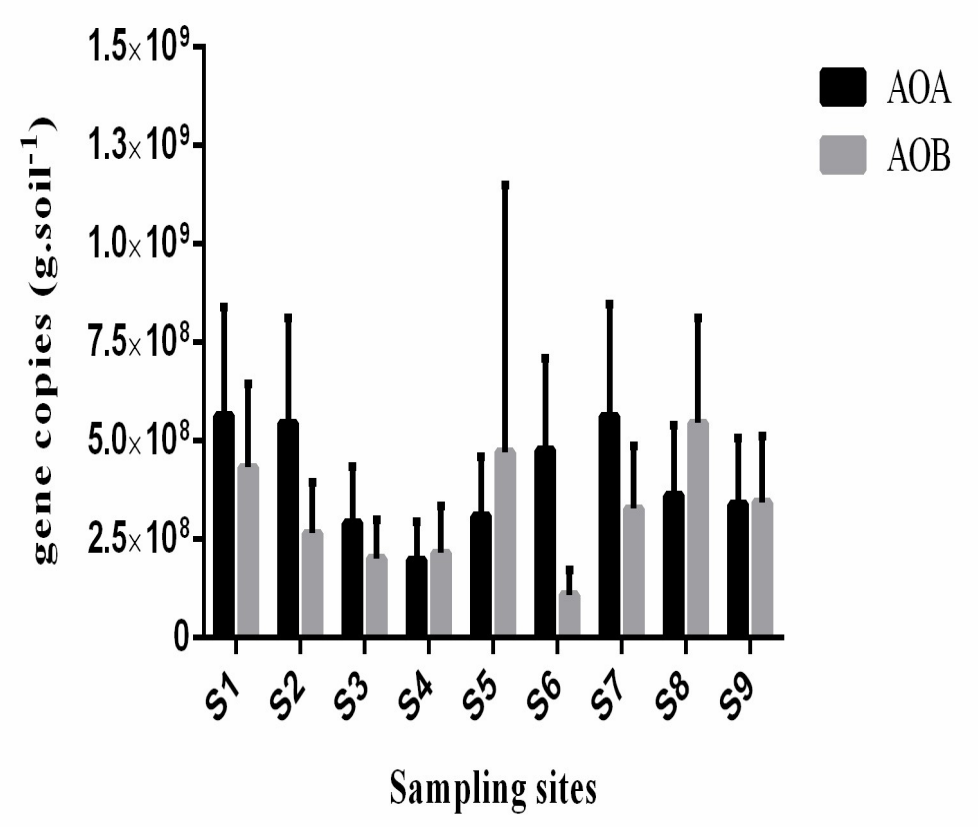

Figure 6. Abundance of (AOA) ammonia oxidizing archaea, and (AOB) ammonia oxidizing bacteria gene copies in samples. Standard errors were estimated from triplicate an analysis within a single qPCR.

Spearman's correlation coefficient was used to describe the ammonia-oxidizing group abundance of $16 \mathrm{~S}$ rRNA, AOA, and AOB (Supplementary Figure S2). The temperature and concentrations of total nitrogen $(\mathrm{TN}), \mathrm{Mg}$, free cyanide $(\mathrm{CN}), \mathrm{SO}_{4}$, and $\mathrm{NH}_{4}$ were not correlated with the overall ammoniaoxidizing community abundance or composition (based on CCA and Spearman's correlations).

The relative abundance of some individual AOA and AOB was negatively correlated with phosphorus and conductivity ( $p<0.01$; Supplementary Figure S2). However, the abundance of AOA and AOB was positively correlated with ORP, $\mathrm{DO}, \mathrm{NO}_{3}$, and $\mathrm{pH}(p<0.05)$.

\subsection{Physical and Chemical Characteristics}

The seasonal ecological parameters indicate that the site samples were influential as evidenced by the variability in many characteristics (Table 1). Our study observed that the conductivity (Cond), oxidation-reduction potential (ORP), sulfate $\left(\mathrm{SO}_{4}^{-2}\right)$, and total nitrogen $(\mathrm{TN})$ at $\mathrm{S} 9$ were relatively higher than at other stations. Moreover, lower $\mathrm{pH}$ was observed at $\mathrm{S} 4$. The other environmental parameters, although variable, did not appear consistent between seasons or sites. 
Table 1. Mean standard deviations ( \pm SD) values of Seasonal physical and chemical environmental Parameters (May, August, and October 2017)

\begin{tabular}{|c|c|c|c|c|c|c|c|c|c|c|}
\hline & Unit & S1 & $\mathrm{S2}$ & S3 & $\mathrm{S} 4$ & S5 & S6 & S7 & S8 & S9 \\
\hline $\mathrm{DO}$ & mg. $\mathrm{L}^{-1}$ & $9.26 \pm 0.01$ & $9.24 \pm 0.01$ & $9.53 \pm 0.02$ & $11.62 \pm 0.01$ & $8.33 \pm 0.1$ & $6.45 \pm 0.02$ & $11.31 \pm 0.01$ & $7.73 \pm 0.01$ & $5.7 \pm 0.02$ \\
\hline $\mathrm{pH}$ & - & $8.52 \pm 0.24$ & $7.1 \pm 0.21$ & $7.8 \pm 0.1$ & $6.58 \pm 0.1$ & $7.6 \pm 0.001$ & $7.3 \pm 0.001$ & $8.73 \pm 0.1$ & $7.73 \pm 0.001$ & $7.49 \pm 0.001$ \\
\hline $\mathrm{NH}_{4}$ & mg.L-1 & $0.043 \pm 0.127$ & $0.013 \pm 0.01$ & $0.083 \pm 0.01$ & $0.087 \pm 0.01$ & $0.02 \pm 0.001$ & $0.06 \pm 0.001$ & $0.15 \pm 0.01$ & $0.06 \pm 0.001$ & $0.68 \pm 0.21$ \\
\hline $\mathrm{CN}$ & mg. $L^{-1}$ & 0.001 & 0.001 & 0.001 & 0.001 & 0.001 & 0.001 & 0.005 & 0.001 & 0.003 \\
\hline $\mathrm{SO}_{4}$ & $\mathrm{mg} \cdot \mathrm{L}^{-1}$ & $9.33 \pm 0.52$ & $9 \pm 0.43$ & $9.33 \pm 0.2$ & $15 \pm 0.1$ & $7.66 \pm 0.01$ & $9.33 \pm 1.02$ & $13 \pm 0.1$ & $15.3 \pm 0.6$ & $16.67 \pm 1.95$ \\
\hline $\mathrm{NO}_{2}$ & mg.L-1 & 0.009 & 0.031 & 0.009 & 0.006 & 0.005 & 0.009 & 0.02 & 0.033 & 0.375 \\
\hline $\mathrm{NO}_{3}$ & mg.L-1 & $0.45 \pm 0.124$ & $0.31 \pm 0.177$ & $0.39 \pm 0.02$ & $0.023 \pm 0.013$ & $0.12 \pm 0.125$ & $0.033 \pm 0.02$ & $0.35 \pm 0.01$ & $0.36 \pm 0.01$ & $0.47 \pm 0.01$ \\
\hline $\mathrm{TN}$ & mg.L-1 & $1.97 \pm 0.468$ & $1.6 \pm 0.177$ & $0.65 \pm 0.03$ & $1.9 \pm 1.34$ & $0.87 \pm 0.2$ & $3.63 \pm 1.03$ & $1.67 \pm 0.234$ & $1 \pm 0.815$ & $7.97 \pm 1.21$ \\
\hline $\mathrm{Mg}$ & mg.L-1 & $0.74 \pm 0.08$ & $1.38 \pm 0.03$ & $1.2 \pm 0.01$ & $0.76 \pm 0.174$ & $1.4 \pm 0.03$ & $1.36 \pm 0.124$ & $1.37 \pm 0.001$ & $1.28 \pm 0.01$ & $2.79 \pm 1.12$ \\
\hline $\mathrm{Ca}$ & mg.L-1 & $1.5 \pm 0.031$ & $2.4 \pm 0.231$ & $2.395 \pm 0.12$ & $2.596 \pm 0.11$ & $2.73 \pm 0.02$ & $2.75 \pm 0.14$ & $2.67 \pm 0.01$ & $3.02 \pm 0.01$ & $1.19 \pm 0.21$ \\
\hline TSS & mg.L. $\mathrm{L}^{-1}$ & $1 \pm 0.02$ & $2 \pm 0.1$ & $1 \pm 3.412$ & $1 \pm 1.541$ & $4.33 \pm 1.31$ & $0.67 \pm 0.42$ & $12.33 \pm 2.01$ & $5 \pm 2.31$ & $11 \pm 3.66$ \\
\hline ORP & $\mathrm{mV}$ & $141.63 \pm 3.89$ & $137.33 \pm 3.22$ & $132.03 \pm 4.26$ & $124 \pm 4.51$ & $91.43 \pm 11.18$ & $103.57 \pm 5.57$ & $67.03 \pm 1.43$ & $92.83 \pm 1.47$ & $-65.067 \pm 1.5$ \\
\hline Cond & $\mu S . \mathrm{cm}^{-1}$ & $65.07 \pm 5.79$ & $130.67 \pm 5.97$ & $131.67 \pm 5.65$ & $96.37 \pm 4.61$ & $119.5 \pm 3.14$ & $137.17 \pm 3.84$ & $158.53 \pm 3.2$ & $163.83 \pm 4.01$ & $612.67 \pm 14.11$ \\
\hline $\mathrm{P}$ & mg.L-1 & $7.47 \pm 0.003$ & $7.537 \pm 0.001$ & $7.539 \pm 0.001$ & $7.54 \pm 0.003$ & $7.605 \pm 0.001$ & $7.599 \pm 0.001$ & $7.606 \pm 0.001$ & $7.617 \pm 0.001$ & $7.59 \pm 0.001$ \\
\hline Temp & ${ }^{\circ} \mathrm{C}$ & $17.4 \pm 0.33$ & $19 \pm 0.1$ & $20 \pm 0.01$ & $20.73 \pm 0.77$ & $19.75 \pm 0.02$ & $19.8 \pm 0.01$ & $21.7 \pm 0.01$ & $19.7 \pm 0.32$ & $21.96 \pm 0.41$ \\
\hline
\end{tabular}

DO, dissolved oxygen; CN, free cyanide; TSS, total suspended solids; ORP, oxidation-reduction potential; Cond, conductivity; TN, total nitrogen; P, phosphorus; Temp, temperature; $\mathrm{mV}$, milli-volts. 


\section{Discussion}

Limited studies have concentrated on the ammonia-oxidizing communities in stream sediments. This research focused on the abundance of microbial community construction and the effects of specific parameters on $\mathrm{AOA}$ and $\mathrm{AOB}$ groups along streams south of the Dabie Mountains (from upstream to downstream), China. The phylogenetic analysis of the AOA amoA communities in the rivers and sediments showed that most of the revealed sequences $(90.0 \%-97.0 \%)$ in the nine sampling sites were linked with Nitrososphaera viennensis and Nitrosopumilus sp clusters I.2, I.3, and I.4 [24]. N. viennensis and Nitrosopumilus sp (moderately) (Figure 2) were extracted from sediments, which could autotrophically or heterotrophically, or even mixotrophically, be involved in ammonia oxidation in freshwater and sediment environments [25]. Yang et al. [26] reported that Nitrososphaera-like microbes were the major AOA groups in sediments of freshwater in the Qinghai-Tibetan Plateau. This result was in agreement with a previous analysis focused on global amoA gene distribution and diversity [27]. It was found that AOA related to this subcluster may appear as a significant function of ammonia oxidation in the sediments of the sampled stream sites; most of the operational taxonomic units (OTUs) obtained were grouped within one cluster in the Nitrososphaera. Our results are in agreement with previous reports that most of the sediment-expected AOA sequences were dominated by cluster I (Figure 2) in neutral pH [28]; $N$. viennensis was enriched by the availability of ammonia as the initiator [29], and N. gargensis has been observed commonly in subtropical zones [30]. The habitats with acidic $\mathrm{pH}$ had a variety of AOA correlated with Nitrosotalea linked with an acidic soil environment [31]. Sequences connected to Nitrosotalea cluster I.1 were revealed at S4, where the $\mathrm{pH}$ was 6.5. It is apparent that Nitrosotalea devanaterra cannot grow at neutral $\mathrm{pH}$ [32], while acidophilic ammonia oxidation hints at novel physiological mechanisms in $N$. devanaterra, which appears to have the greatest substrate affinity for AOA [33]. This phenomenon contradicted the results of a previous study [34], which showed that the acidophilic AOA Nitrosotalea devanaterra and Nitrosotalea sp lived at an optimal pH ranged between 4 and 5 [35] and were totally prevented if the $\mathrm{pH}$ increased to 6.5. Nevertheless, our findings indicated the presence of some adapted species related to the Nitrosotalea cluster that can resist a comparably acidic $\mathrm{pH}$ (>6.5). Furthermore, our findings imply that, regarding the physiologic adaptation of microbial guilds to environmental pressure [36-38], most of the OTUs found in the sampling sites (more neutral $\mathrm{pH}$ ) were correlated with sequences of freshwater [39-41]. Out of the AOB genes (Supplementary Figure S1), 61 sequences were collected, and these sequences were clustered into three OTUs. With a $99 \%$ similarity for each OTU, as previously predicted [42], Nitrosomonas cluster is usually found in river ecosystems [43]. Our results also confirmed this phenomenon; $99.7 \%$ of the total AOB sequences were obtained from S7 and S9 downstream. Furthermore, our investigation indicates that some sites did not obtain OTU numbers (Supplementary Table S3), and this may be due to the environmental factors [44] and high similarity sequences [45].

Principal component analysis (PCA) was used to measure the environmental characteristics, especially in sediment samples. PCA1 and PCA2 accounted for $50.38 \%$ and $23.02 \%$ of the variation, respectively (Figure 3). CCA analysis showed that dissolved oxygen and phosphorus are powerful parameters influencing the dynamics of amoA functional genes (Figure 4). This agrees with a previous study [46], which suggested that DO is one of the most correlated factors in the amo $A$ gene community. In the current investigation, the sampling sites from upstream to downstream revealed that, through CCA, the spatial distribution of the depositional environment of AOA and AOB is potentially related to ORP. This result could be linked to previous studies $[47,48]$ in which the changes in ORP and $\mathrm{pH}$ values were linked to ammonia-oxidizing microbial communities in the Luotian River. Interestingly, the community of ammonia oxidizers showed an inverse relationship between ORP and phosphorus [49,50]. Some environmental factors did not influence gene abundance of AOA and AOB in the same way, suggesting 
that environmental factors have various influences on these communities, as seen in previous studies [51,52]. Together, these data suggest an inverse relationship between phosphorus and ORP, and the primary factors influence the community of ammonia oxidizers.

Our investigation shows that $3 \%-14 \%$ of the clones were related to the Cyanobacteria phylum, which was discussed previously [53]. In our filtered sequences, we detected 125 bacterial phyla across all sediment samples with the Ribosomal Database Project (RDP) Classifier. The prevalent groups $(<1 \%$ abundance) of each sample are shown in Figure 5. Proteobacteria (19\%-52\%) was the most abundant species. This result could be linked to a previous study [54,55] that, confirmed that Betaproteobacteria could be classified as the one dominant group in the ecosystem of streams during May, August, and October. Our investigation showed that Bacteroidetes did not appear in May (abundance $>1 \%$ ), suggesting that Bacteroidetes was present in low numbers, was missed in those selected points, or did not perfectly amplify with the PCR primers. In reality, the absence of the group in a small percentage of the abundance communities is not the challenge in most cases [56].

In this investigation, the gene copy ratios of AOA were higher than those of AOB at the upstream S6 and S7 sites (Figure 6), which confirmed the previous investigations of AOA dominance in many environments [57,58]. At S4, S5, and S8 (downstream), the AOB genes were slightly more numerous than AOA, as confirmed in previous studies looking into locations such as lakes [59], estuaries [2], and sediments [60]. The AOA and $\mathrm{AOB}$ communities appeared at many locations and periods. Despite the $\mathrm{pH}, \mathrm{AOA}$ and $\mathrm{AOB}$ abundance was high (3.92E+8 to $3.60 \mathrm{E}+8$ gene copies per $\mu \mathrm{g}$ DNA extract) at site S4, with $\mathrm{pH}$ as low as 6.5. Due to consequent decreased $\mathrm{pH}$ in the bioavailability of nitrogen, acidic environments might preference AOA dominance over AOB because of their significant correlation with ammonia [41,61]. Various results of the comparative abundance of AOB and AOA have been reported in streams. However, the environmental factors that affect relative abundance are not well understood.

Briefly, we chose nine specific stream sites as target locations to find clear differences in the sediments and bacteria communities, as well as a linkage of biotic factors to environmental characteristics (Table 1). The physicochemical properties of the rivers varied among the evolutionary stages of the four streams and were responsible for the differences in nitrification. At the upstream sites (S1, S2, and S3), these properties were more suitable than those from S9, indicating the general environmental quality (far from human activities) of the S5, S6, and S7 sites. Many environmental factors reflected some effect on the amoA gene community, including oxygen availability [62], phosphorus [63,64], sulfide [65], $\mathrm{pH}[66,67]$, soil type [68], $\mathrm{NH}_{4}{ }^{+}-\mathrm{N}$, and $\mathrm{NO}_{3}-\mathrm{N}$ [69]. However, these indicators did not have an appreciable impact on archaeal or bacterial ammonia oxidation. Therefore, further investigations are required in the future to prove this linkage

\section{Materials and Methods}

\subsection{Site and Sampling}

The study was carried out in Luotian, Huanggang City, Hubei Province, south of the Dabie Mountains, China $\left(30^{\circ} 35^{\prime} \mathrm{N}, 115^{\circ} 06^{\prime} \mathrm{E}\right)$ (Figure 1). This location is characterized by a series of mountains covered by forests $(70 \%)$. Five streams originate from the Dabie Mountains and flow to the southwest. They meet the Ba River and then flow inward into the Yangtze River.

Various chemical and physical parameters - oxidation-reduction potential (ORP), temperature (Temp), total suspended solids (TSS), conductivity (Cond), $\mathrm{pH}$, and dissolved oxygen (DO)-were measured using a multiparameter probe (YSI Professional Plus). Moreover, magnesium (Mg), calcium $(\mathrm{Ca})$, nitrate $\left(\mathrm{NO}_{3}{ }^{-}\right)$, ammonia $\left(\mathrm{NH}_{4}{ }^{+}\right)$, nitrite $\left(\mathrm{NO}_{2}-\right)$, total nitrogen $(\mathrm{TN})$, sulfate $\left(\mathrm{SO}_{4}{ }^{-2}\right)$, free cyanide $(\mathrm{CN})$, and phosphorus $\left(\mathrm{PO}^{-3}-\mathrm{P}\right)$ were analyzed by electronic spectrophotometer (Hach model DR2800, Hach 
Company, Loveland, CO, USA). Estimation of environmental parameters was carried out in triplicate in the covered sediment samples, according to standard methods [70].

\subsection{Collection of Samples}

The samples were collected from 9 stations (S1 to S9) (Figure 1). The samples were taken from each of the 3 branches at S1, S2, and S3 (upstream) and 4 other locations, S4, S5, S6, and S7 (human influence); one stream had a length of $78.2 \mathrm{~km}$, from S9 (discharge of waste treatment plant) and from S8 (downstream). The surface water from 0.5 to $5 \mathrm{~m}$ in each site in the stream was picked up (15 L). The water was fully mixed following filtration experiment methods as described previously [71]. The filter was preserved immediately in liquid nitrogen to convey to the laboratory. Sediments were collected from the same side as the water collection at each of the 9 stations at the $0-5 \mathrm{~cm}$ level. Several soil samples were compounded for a microbial sample (50-100 g). Sediments were also preserved in an impermeable sampling packet in liquid nitrogen and transported to the laboratory. All samples were conserved at -80 ${ }^{\circ} \mathrm{C}$ before DNA extraction.

\subsection{Nucleic Acid Extraction, PCR, Cloning, and Sequencing}

Microbial organisms from the environmental sediments were studied by extracting DNA using the fast DNA ${ }^{\mathrm{TM}}$ spin kit for soil (MP Biomedicals, Solon, OH, USA). Consequently, a NanoDrop (2000c) spectrophotometer (Wilmington, DE, USA) was used to quantify the DNA according to the manufacturer's standards.

The major cycling program for each primer set and the primers' names are listed in Supplementary Table S1. The PCR amplification was performed with a peqSTAR $2 \times$ double block thermocycler, (PEQLAB Biotechnologie GMBH, Erlangen, Germany), using the following conditions: $50 \mu \mathrm{L}$ mixture comprising $25 \mu \mathrm{L} 2 \times$ Master Mix (Thermo Fisher Scientific, USA), $0.2 \mu \mathrm{M}$ of each primer, and 50-100 ng of DNA. Thermal cycling was carried out by an initial denaturation step for $5 \mathrm{~min}$ at $95{ }^{\circ} \mathrm{C}$. The presence and sizes of the PCR amplification products were determined by agarose (1\%) gel electrophoresis.

Clone libraries of $\mathrm{AOA}$ and $\mathrm{AOB}$ amoA gene-amplified products from all the sampling sites were constructed following a previously described method [72]. Briefly, after DNA extraction and PCR amplification of the amoA genes, the mixture of PCR products was gel-purified and cloned with a pMD19-T cloning kit (Takara). More than 30 clones were randomly picked from each clone library and verified for correct insertion of DNA fragment by PCR amplification with primer set M13F and M13R. PCR products from the positive clones were sequenced by ABI $3730 \times 1$ sequencer (Wuhan, China). DNA sequences were analyzed and edited using BioEdit software version 5.07 and MEGA version 7.

\subsection{Phylogenetic Analysis}

The sequences were first cropped. Then the vectors, primers, and alignments were completed by ClustalW and analyzed by BLASTn corresponding to the nonrepetitive National Center for Biotechnology Information (NCBI) database [73]. Operational taxonomic units (OTUs) were determined as groups where the sequence identities were performed greater than $90 \%$ using the Ribosomal Database Project (RDP) (http://rdp.cme.msu.edu and https://www.mothur.org). Phylogenetic trees were created using MEGA 7, the neighbor-joining method of reference [74], (http://www.phylogeny.fr), and FigTree v1.4.3. All OTU sequences of $16 \mathrm{~S}$ rRNA, AOA, and BOA were deposited in the NCBI database under accession numbers MG238515-MG238543 and MG519671-MG519707.

\subsection{Real-Time Quantitative PCR}


Functional genes related to nitrification were measured in the sediment samples collected during May, August, and October 2017 from a $0.5-5 \mathrm{~cm}$ depth at each station. The bacterial concentration was defined in triplicate by amplification of the 16S rRNA (archaeal and bacterial) part using the primers and PCR conditions [75]. The primers used for this study are tabulated in Supplementary Table S1. All samples of archaeal and bacterial $16 \mathrm{~S}$ rRNA, AOA, and AOB were quantified by an ABI Prism sequence detection system based on the SYBR Green I method. The $25 \mu \mathrm{L}$ reaction mixtures contained $12.5 \mu \mathrm{L}$ of SYBR Premix Ex TaqTM (Takara, China), $1 \mu \mathrm{L}$ of the forward and reverse primer, and $1 \mu \mathrm{L}$ of template DNA. The specificity of the PCR for each target gene was verified by the generation of melting curves and agarose gel electrophoresis. All samples were assayed in triplicate.

Tenfold serial dilutions of a known copy number of the plasmid DNA were subjected to real-time PCR assay in triplicate to generate an external standard curve. The sequences were matched with each

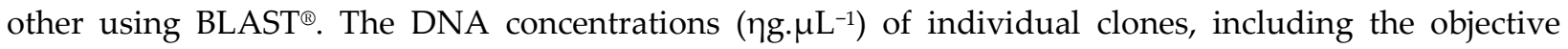
sequences of 16S rRNA, AOA, and AOB, were determined by NanoDrop 2000c spectrophotometer (Wilmington, DE, USA) and transformed to copy numbers of DNA per $\mu \mathrm{L}$, which were determined using a program accessible at http://cels.uri.edu/gsc/cndna.html.

\subsection{Statistical Analysis}

The correlation between the environmental parameters and sampling sites was determined using PAST v.3.15 [23] and represented in the form of principal component analysis (PCA). To understand the strength of the correlation between the parameters, canonical correspondence analysis (CCA) was carried out using Excel add-in XLSTAT 2017. Spearman's correlation was used for the analysis of correlations among the abundance of $\mathrm{AOA}, \mathrm{AOB}$, and environmental dynamics. Relative abundance of the clones was used as the input of species. Two ecological indices, the Shannon-Weiner index $\left(\mathrm{H}^{\prime}\right)[76]$ and the Simpson index (D) [77], were calculated using the number of OTUs. We used the algorithm in BLASTn to define the most homogeneous sequences. The aligned sequences were converted into amino acids by applying MEGA 7 and used for the assembly of phylogenetic tree neighbor-joining by using Poisson model distances and pairwise deletion of gaps and missing data. Bootstrapping (1000 replicates restructured) was used for phylogenetic restructuring.

\section{Conclusion}

In conclusion, our results suggest that the abundance of AOA genes was higher than AOB genes at most of these sites, reflecting the influence of environmental characteristics on the abundance and diversity of ammonia-oxidizing communities at various streams. Ammonia oxidizer groups were significantly correlated with dissolved oxygen and ORP. Our results surprisingly indicated that some species might be related to the Nitrosotalea cluster, which resists comparably low acidic $\mathrm{pH}(>6.5)$. Furthermore, it is implied that the physiological adaptation of microbial guilds to environmental pressure might describe a fundamental niche of ammonia-oxidizing communities in natural habitats. Interestingly, this investigation provides a hint to the linkage between the amoA gene and ORP, which may be the primary factor influencing ammonia-oxidizing communities. Finally, these data could assist further researchers to establish significant studies concerning nitrogen cycling in stream ecosystems.

Supplementary Materials: S1: Phylogenetic tree the neighbor-joining showing the phylogenetic relationships of ammonia oxidizing bacteria (AOB) gene sequences. Bootstrap support values (1000 replicates). The scale bar represents 0.2; evolutionary analyses were implemented in MEGA 7, Figure S2: Spearman correlation matrix representative significant relationships between investigation parameters, for correlations among log-transformed qPCR data, gene copies (g.soil ${ }^{-1}$ ), and physicochemical data of environments samples. The colors of the scale bar indicate the nature of the correlation with 1 denoting perfect positive correlation (green), and -1 denoting perfect negative correlation (red) were tested at $p<0.01$ and $p<0.05$. The used geo-physicochemical data of the samples 
applied to Xlstat (www.xlstat.com), Table S1: The PCR primer pairs and thermal programs, Table S2: Gene copy numbers of $16 S$ rRNA bacteria and archaea (stream and sediment), ammonia oxidizing archaea (AOA), and ammonia oxidizing bacteria (AOB) in sampling sites. Values and standard deviations were estimated from triplicate an analysis within a single qPCR, Table S3: Comparison of AOA and AOB diversities as well as coverage estimates in sampling sites base on $95 \%$ nucleotide sequences similarity.

Authors Contributions: Amjed Ginawi and Yan Yunjun conceived the study. Amjed Ginawi and Wang Lixiao selected the measures and planned the data collection. Huading Wang and Bingbing Yu ran the analyses. Amjed Ginawi and Yan Yunjun wrote the manuscript. All the authors approved the final manuscript for submission.

Ethical approval: This article does not contain any studies with human participants or animals performed by any of the authors.

Acknowledgments: This work is financially supported by the National Natural Science Foundation of China (grant No. 31070089, 31170078, and J1103514), the National High Technology Research and Development Program of China (grant Nos. 2013AA065805 and 2014AA093510), the National Natural Science Foundation of Hubei Province (grant No. 2015CFA085), and the Fundamental Research Funds for HUST (grant Nos. 2014NY007, 2017KFYXJJ212, 2017KFXKJC010, 2017KFTSZZ001). Many thanks are indebted to the Analytical and Testing Center of Huazhong University of Science and Technology for the measurements of water quality.

Conflict of interest: The authors declare that they have no competing interests. 


\section{References}

1. Wang, J.; He, Y.; Zhu, J.; Guan, H.; Huang, M. Screening and optimizing of inhibitors for ammonia-oxidizing bacteria in sediments of malodorous river. Appl Microbiol Biotechnol 2017, 101, 6193-6203.doi: 10.1007/s00253017-8318-1.

2. Li, J.; Nedwell, D.B.; Beddow, J.; Dumbrell, A.J.; McKew, B.A.; Thorpe, E.L.; Whitby, C. Amoa gene abundances and nitrification potential rates suggest that benthic ammonia-oxidizing bacteria and not archaea dominate $\mathrm{n}$ cycling in the colne estuary, united kingdom. Appl Environ Microbiol 2015, 81, 159-165.doi: 10.1128/AEM.02654-14.

3. Schleper, C.; Nicol, G.W. Ammonia-oxidising archaea--physiology, ecology and evolution. Adv Microb Physiol 2010, 57, 1-41.doi: 10.1016/B978-0-12-381045-8.00001-1.

4. Nelson, K.N.; Neilson, J.W.; Root, R.A.; Chorover, J.; Maier, R.M. Abundance and activity of 16s rrna, amoa and nifh bacterial genes during assisted phytostabilization of mine tailings. Int J Phytoremediation 2015, 17, 493502.doi: 10.1080/15226514.2014.935284.

5. Rotthauwe, J.H.; Witzel, K.P.; Liesack, W. The ammonia monooxygenase structural gene amoa as a functional marker: Molecular fine-scale analysis of natural ammonia-oxidizing populations. Applied and Environmental Microbiology 1997, 63, 4704-4712.

6. Kumar, S.; Nicholas, D.J.D. Proton electrochemical gradients in washed cells of nitrosomonas europaea and nitrobacter agilis. JOURNAL OF BACTERIOLOGY 1982, 154, 65-71.

7. Antoniou, P.; Hamilton, J.; Koopman, B.; Jain, R.; Holloway, B.; Lyberatos, G.; Svoronos, S.A. Effect of temperature and ph on the effective maximum specific growth rate of nitrifying bacteria. Water Research 1990, 24, 97-101.doi: 10.1016/0043-1354(90)90070-m.

8. Hagopian, D.S.; Riley, J.G. A closer look at the bacteriology of nitrification. Aquacultural Engineering 1998, 18, 223-244.doi: 10.1016/s0144-8609(98)00032-6.

9. Xue, Y.; Song, J.X.; Zhang, Y.; Kong, F.H.; Wen, M.; Zhang, G.T. Nitrate pollution and preliminary source identification of surface water in a semi-arid river basin, using isotopic and hydrochemical approaches. Water 2016, 8, 328.doi: 10.3390/w8080328.

10. Jiang, B.; Chen, J.; Luo, Q.; Lai, J.; Xu, H.; Wang, Y.; Yu, K. Long-term changes in water quality and eutrophication of china's liujiang river. Polish Journal of Environmental Studies 2016, 25, 1033-1043.doi: 10.15244/pjoes/61819.

11. Siliakus, M.F.; van der Oost, J.; Kengen, S.W.M. Adaptations of archaeal and bacterial membranes to variations in temperature, ph and pressure. Extremophiles 2017, 21, 651-670.doi: 10.1007/s00792-017-0939-x.

12. Sahrawat, K.L. Factors affecting nitrification in soils. Communications in Soil Science and Plant Analysis 2008, 39, 1436-1446.doi: 10.1080/00103620802004235.

13. Leininger, S.; Urich, T.; Schloter, M.; Schwark, L.; Qi, J.; Nicol, G.W.; Prosser, J.I.; Schuster, S.C.; Schleper, C. Archaea predominate among ammonia-oxidizing prokaryotes in soils. Nature 2006, 442, 806-809.doi: 10.1038/nature04983.

14. Zheng, L.; Zhao, X.; Zhu, G.; Yang, W.; Xia, C.; Xu, T. Occurrence and abundance of ammonia-oxidizing archaea and bacteria from the surface to below the water table, in deep soil, and their contributions to nitrification. Microbiologyopen 2017, 6.doi: 10.1002/mbo3.488.

15. Cydzik-Kwiatkowska, A.; Zielinska, M. Bacterial communities in full-scale wastewater treatment systems. World J Microbiol Biotechnol 2016, 32, 66.doi: 10.1007/s11274-016-2012-9.

16. Li, J.; Huang, B.; Wang, Q.; Li, Y.; Fang, W.; Han, D.; Yan, D.; Guo, M.; Cao, A. Effects of fumigation with metam-sodium on soil microbial biomass, respiration, nitrogen transformation, bacterial community diversity and genes encoding key enzymes involved in nitrogen cycling. Science of The Total Environment 2017, 598, 10271036.doi: 10.1016/j.scitotenv.2017.02.058.

17. Magdziak, Z.; Gąsecka, M.; Goliński, P.; Mleczek, M. Phytoremediation and environmental factors. Springer 2015, 2, 45-55.doi: 10.1007/978-3-319-10395-2_4. 
18. Ma, Y.; He, X.; Qi, K.; Wang, T.; Qi, Y.; Cui, L.; Wang, F.; Song, M. Effects of environmental contaminants on fertility and reproductive health. Journal of Environmental Sciences 2018.doi: 10.1016/j.jes.2018.07.015.

19. Rockstrom, J.; Steffen, W.; Noone, K.; Persson, A.; Chapin, F.S., 3rd; Lambin, E.F.; Lenton, T.M.; Scheffer, M.; Folke, C.; Schellnhuber, H.J., et al. A safe operating space for humanity. Nature 2009, 461, 472-475.doi: 10.1038/461472a.

20. Schullehner, J.; Stayner, L.; Hansen, B. Nitrate, nitrite, and ammonium variability in drinking water distribution systems. Int J Environ Res Public Health 2017, 14.doi: 10.3390/ijerph14030276.

21. Fierer, N.; Jackson, R.B. The diversity and biogeography of soil bacterial communities. Proc Natl Acad Sci U S A 2006, 103, 626-631.doi: 10.1073/pnas.0507535103.

22. Lauber, C.L.; Hamady, M.; Knight, R.; Fierer, N. Pyrosequencing-based assessment of soil ph as a predictor of soil bacterial community structure at the continental scale. Appl Environ Microbiol 2009, 75, 5111-5120.doi: 10.1128/AEM.00335-09.

23. Hammer, Ø.; Harper, D.T.; Ryan, P.D. Past: Paleontological statistics software package for education and data analysis. Palaeontologia Electronica 2001, 4, 4-9.

24. Xi, R.; Long, X.E.; Huang, S.; Yao, H. Ph rather than nitrification and urease inhibitors determines the community of ammonia oxidizers in a vegetable soil. AMB Express 2017, 7, 129.doi: 10.1186/s13568-017-0426-x.

25. Liu, R.; Hayden, H.; Suter, H.; He, J.Z.; Chen, D.L. The effect of nitrification inhibitors in reducing nitrification and the ammonia oxidizer population in three contrasting soils. Journal of Soils and Sediments 2015, 15, 1113-1118.doi: 10.1007/s11368-015-1086-6.

26. Yang, J.; Jiang, H.; Dong, H.; Wang, H.; Wu, G.; Hou, W.; Liu, W.; Zhang, C.; Sun, Y.; Lai, Z. Amoa-encoding archaea and thaumarchaeol in the lakes on the northeastern qinghai-tibetan plateau, china. Front Microbiol 2013, 4, 329.doi: 10.3389/fmicb.2013.00329.

27. Pester, M.; Rattei, T.; Flechl, S.; Grongroft, A.; Richter, A.; Overmann, J.; Reinhold-Hurek, B.; Loy, A.; Wagner, M. Amoa-based consensus phylogeny of ammonia-oxidizing archaea and deep sequencing of amoa genes from soils of four different geographic regions. Environ Microbiol 2012, 14, 525-539.doi: 10.1111/j.14622920.2011.02666.x.

28. Taylor, A.E.; Giguere, A.T.; Zoebelein, C.M.; Myrold, D.D.; Bottomley, P.J. Modeling of soil nitrification responses to temperature reveals thermodynamic differences between ammonia-oxidizing activity of archaea and bacteria. ISME J 2017, 11, 896-908.doi: 10.1038/ismej.2016.179.

29. Tourna, M.; Stieglmeier, M.; Spang, A.; Konneke, M.; Schintlmeister, A.; Urich, T.; Engel, M.; Schloter, M.; Wagner, M.; Richter, A., et al. Nitrososphaera viennensis, an ammonia oxidizing archaeon from soil. Proc Natl Acad Sci U S A 2011, 108, 8420-8425.doi: 10.1073/pnas.1013488108.

30. Kim, J.G.; Jung, M.Y.; Park, S.J.; Rijpstra, W.I.; Sinninghe Damste, J.S.; Madsen, E.L.; Min, D.; Kim, J.S.; Kim, G.J.; Rhee, S.K. Cultivation of a highly enriched ammonia-oxidizing archaeon of thaumarchaeotal group i.1b from an agricultural soil. Environ Microbiol 2012, 14, 1528-1543.doi: 10.1111/j.1462-2920.2012.02740.x.

31. Gubry-Rangin, C.; Nicol, G.W.; Prosser, J.I. Archaea rather than bacteria control nitrification in two agricultural acidic soils. FEMS Microbiol Ecol 2010, 74, 566-574.doi: 10.1111/j.1574-6941.2010.00971.x.

32. Lehtovirta-Morley, L.E.; Sayavedra-Soto, L.A.; Gallois, N.; Schouten, S.; Stein, L.Y.; Prosser, J.I.; Nicol, G.W. Identifying potential mechanisms enabling acidophily in the ammonia-oxidizing archaeon "candidatus nitrosotalea devanaterra". Appl Environ Microbiol 2016, 82, 2608-2619.doi: 10.1128/AEM.04031-15.

33. Lehtovirta-Morley, L.E.; Stoecker, K.; Vilcinskas, A.; Prosser, J.I.; Nicol, G.W. Cultivation of an obligate acidophilic ammonia oxidizer from a nitrifying acid soil. Proc Natl Acad Sci U S A 2011, 108, 15892-15897.doi: 10.1073/pnas.1107196108.

34. Liu, S.; Shen, L.; Lou, L.; Tian, G.; Zheng, P.; Hu, B. Spatial distribution and factors shaping the niche segregation of ammonia-oxidizing microorganisms in the qiantang river, china. Appl Environ Microbiol 2013, 79, 4065-4071.doi: 10.1128/AEM.00543-13.

35. Gubry-Rangin, C.; Hai, B.; Quince, C.; Engel, M.; Thomson, B.C.; James, P.; Schloter, M.; Griffiths, R.I.; Prosser, J.I.; Nicol, G.W. Niche specialization of terrestrial archaeal ammonia oxidizers. Proc Natl Acad Sci U S A 2011, 108, 21206-21211.doi: 10.1073/pnas.1109000108. 
36. Li, Y.Y.; Chapman, S.J.; Nicol, G.W.; Yao, H.Y. Nitrification and nitrifiers in acidic soils. Soil Biol Biochem 2018, 116, 290-301.doi: 10.1016/j.soilbio.2017.10.023.

37. Lehtovirta-Morley, L.E.; Ge, C.; Ross, J.; Yao, H.; Nicol, G.W.; Prosser, J.I. Characterisation of terrestrial acidophilic archaeal ammonia oxidisers and their inhibition and stimulation by organic compounds. FEMS Microbiol Ecol 2014, 89, 542-552.doi: 10.1111/1574-6941.12353.

38. Wang, B.; Zheng, Y.; Huang, R.; Zhou, X.; Wang, D.; He, Y.; Jia, Z. Active ammonia oxidizers in an acidic soil are phylogenetically closely related to neutrophilic archaeon. Appl Environ Microbiol 2014, 80, 1684-1691.doi: 10.1128/AEM.03633-13.

39. Mosier, A.C.; Allen, E.E.; Kim, M.; Ferriera, S.; Francis, C.A. Genome sequence of "candidatus nitrosoarchaeum limnia" bg20, a low-salinity ammonia-oxidizing archaeon from the san francisco bay estuary. J Bacteriol 2012, 194, 2119-2120.doi: 10.1128/JB.00007-12.

40. Auguet, J.C.; Casamayor, E.O. Partitioning of thaumarchaeota populations along environmental gradients in high mountain lakes. FEMS Microbiol Ecol 2013, 84, 154-164.doi: 10.1111/1574-6941.12047.

41. Ramanathan, B.; Boddicker, A.M.; Roane, T.M.; Mosier, A.C. Nitrifier gene abundance and diversity in sediments impacted by acid mine drainage. Front Microbiol 2017, 8, 2136.doi: 10.3389/fmicb.2017.02136.

42. Fujitani, H.; Kumagai, A.; Ushiki, N.; Momiuchi, K.; Tsuneda, S. Selective isolation of ammonia-oxidizing bacteria from autotrophic nitrifying granules by applying cell-sorting and sub-culturing of microcolonies. Front Microbiol 2015, 6, 1159.doi: 10.3389/fmicb.2015.01159.

43. Zhao, D.Y.; Luo, J.; Zeng, J.; Wang, M.; Yan, W.M.; Huang, R.; Wu, Q.L. Effects of submerged macrophytes on the abundance and community composition of ammonia-oxidizing prokaryotes in a eutrophic lake. Environ Sci Pollut Res Int 2014, 21, 389-398.doi: 10.1007/s11356-013-1909-1.

44. Wei, B.; Yu, X.; Zhang, S.; Gu, L. Comparison of the community structures of ammonia-oxidizing bacteria and archaea in rhizoplanes of floating aquatic macrophytes. Microbiol Res 2011, 166, 468-474.doi: 10.1016/j.micres.2010.09.001.

45. Midgley, D.J.; Greenfield, P.; Shaw, J.M.; Oytam, Y.; Li, D.; Kerr, C.A.; Hendry, P. Reanalysis and simulation suggest a phylogenetic microarray does not accurately profile microbial communities. PLoS One 2012, 7 , e33875.doi: 10.1371/journal.pone.0033875.

46. Wang, X.; Wen, X.; Xia, Y.; Hu, M.; Zhao, F.; Ding, K. Ammonia oxidizing bacteria community dynamics in a pilot-scale wastewater treatment plant. PLoS One 2012, 7, e36272.doi: 10.1371/journal.pone.0036272.

47. Gao, D.-W.; Peng, Y.-Z.; Liang, H.; Wang, P. Using oxidation-reduction potential (orp) and ph value for process control of shortcut nitrification-denitrification. Journal of Environmental Science and Health, Part A 2003, 38, 2933-2942.doi: 10.1081/ese-120025842.

48. Kimbrough, D.E.; Kouame, Y.; Moheban, P.; Springthorpe, S. The effect of electrolysis and oxidation reduction potential on microbial survival, growth, and disinfection. International Journal of Environment and Pollution 2006, 27, 211.doi: 10.1504/ijep.2006.010464.

49. Szogi, A.A.; Hunt, P.G.; Sadler, E.J.; Evans, D.E. Characterization of oxidation-reduction processes in constructed wetlands for swine wastewater treatment. Applied Engineering in Agriculture 2004, 20, 189-200.doi: 10.13031/2013.15891.

50. Zheng, Y.; Hou, L.; Newell, S.; Liu, M.; Zhou, J.; Zhao, H.; You, L.; Cheng, X. Community dynamics and activity of ammonia-oxidizing prokaryotes in intertidal sediments of the yangtze estuary. Appl Environ Microbiol 2014, 80, 408-419.doi: 10.1128/AEM.03035-13.

51. Li, X.; Zhu, Y.-G.; Cavagnaro, T.R.; Chen, M.; Sun, J.; Chen, X.; Qiao, M. Do ammonia-oxidizing archaea respond to soil cu contamination similarly asammonia-oxidizing bacteria? Plant and Soil 2009, 324, 209-217.doi: 10.1007/s11104-009-9947-7.

52. Ouyang, F.; Zhai, H.; Ji, M.; Zhang, H.; Dong, Z. Physiological and transcriptional responses of nitrifying bacteria exposed to copper in activated sludge. J Hazard Mater 2016, 301, 172-178.doi: 10.1016/j.jhazmat.2015.08.039.

53. Peng, Y.; Liu, L.; Jiang, L.; Xiao, L. The roles of cyanobacterial bloom in nitrogen removal. Sci Total Environ 2017, 609, 297-303.doi: 10.1016/j.scitotenv.2017.03.149. 
54. Wu, X.; Xi, W.; Ye, W.; Yang, H. Bacterial community composition of a shallow hypertrophic freshwater lake in china, revealed by 16s rrna gene sequences. FEMS Microbiol Ecol 2007, 61, 85-96.doi: 10.1111/j.15746941.2007.00326.x.

55. ElNaker, N.A.; Yousef, A.F.; Hasan, S.W. Effect of hydraulic retention time on microbial community structure in wastewater treatment electro-bioreactors. Microbiologyopen 2018, 7, e00590.doi: 10.1002/mbo3.590.

56. Ahmed, W.; Hughes, B.; Harwood, V.J. Current status of marker genes of bacteroides and related taxa for identifying sewage pollution in environmental waters. Water 2016, 8, 231.doi: 10.3390/w8060231.

57. Herrmann, M.; Hadrich, A.; Kusel, K. Predominance of thaumarchaeal ammonia oxidizer abundance and transcriptional activity in an acidic fen. Environ Microbiol 2012, 14, 3013-3025.doi: 10.1111/j.14622920.2012.02882.x.

58. Hatzenpichler, R. Diversity, physiology, and niche differentiation of ammonia-oxidizing archaea. Appl Environ Microbiol 2012, 78, 7501-7510.doi: 10.1128/AEM.01960-12.

59. Bollmann, A.; Bullerjahn, G.S.; McKay, R.M. Abundance and diversity of ammonia-oxidizing archaea and bacteria in sediments of trophic end members of the laurentian great lakes, erie and superior. PLoS One 2014, 9, e97068.doi: 10.1371/journal.pone.0097068.

60. Herrmann, M.; Scheibe, A.; Avrahami, S.; Kusel, K. Ammonium availability affects the ratio of ammoniaoxidizing bacteria to ammonia-oxidizing archaea in simulated creek ecosystems. Appl Environ Microbiol 2011, 77, 1896-1899.doi: 10.1128/AEM.02879-10.

61. Martens-Habbena, W.; Berube, P.M.; Urakawa, H.; de la Torre, J.R.; Stahl, D.A. Ammonia oxidation kinetics determine niche separation of nitrifying archaea and bacteria. Nature 2009, 461, 976-979.doi: 10.1038/nature08465.

62. Gleeson, D.B.; Müller, C.; Banerjee, S.; Ma, W.; Siciliano, S.D.; Murphy, D.V. Response of ammonia oxidizing archaea and bacteria to changing water filled pore space. Soil Biology and Biochemistry 2010, 42, 1888-1891.doi: 10.1016/j.soilbio.2010.06.020.

63. Herfort, L.; Schouten, S.; Abbas, B.; Veldhuis, M.J.; Coolen, M.J.; Wuchter, C.; Boon, J.P.; Herndl, G.J.; Sinninghe Damste, J.S. Variations in spatial and temporal distribution of archaea in the north sea in relation to environmental variables. FEMS Microbiol Ecol 2007, 62, 242-257.doi: 10.1111/j.1574-6941.2007.00397.x.

64. Yamashita, T.; Yamamoto-Ikemoto, R. Nitrogen and phosphorus removal from wastewater treatment plant effluent via bacterial sulfate reduction in an anoxic bioreactor packed with wood and iron. Int J Environ Res Public Health 2014, 11, 9835-9853.doi: 10.3390/ijerph110909835.

65. Caffrey, J.M.; Bano, N.; Kalanetra, K.; Hollibaugh, J.T. Ammonia oxidation and ammonia-oxidizing bacteria and archaea from estuaries with differing histories of hypoxia. ISME J 2007, 1, 660-662.doi: 10.1038/ismej.2007.79.

66. Li, H.; Weng, B.S.; Huang, F.Y.; Su, J.Q.; Yang, X.R. Ph regulates ammonia-oxidizing bacteria and archaea in paddy soils in southern china. Appl Microbiol Biotechnol 2015, 99, 6113-6123.doi: 10.1007/s00253-015-6488-2.

67. Zhang, L.M.; Hu, H.W.; Shen, J.P.; He, J.Z. Ammonia-oxidizing archaea have more important role than ammonia-oxidizing bacteria in ammonia oxidation of strongly acidic soils. ISME J 2012, 6, 1032-1045.doi: 10.1038/ismej.2011.168.

68. Huang, R.; Wu, Y.; Zhang, J.; Zhong, W.; Jia, Z.; Cai, Z. Nitrification activity and putative ammoniaoxidizing archaea in acidic red soils. Journal of Soils and Sediments 2011, 12, 420-428.doi: 10.1007/s11368-0110450-4.

69. Li, X.R.; Xiao, Y.P.; Ren, W.W.; Liu, Z.F.; Shi, J.H.; Quan, Z.X. Abundance and composition of ammoniaoxidizing bacteria and archaea in different types of soil in the yangtze river estuary. J Zhejiang Univ Sci B 2012, 13, 769-782.doi: 10.1631/jzus.B1200013.

70. Bailey, B.L.; Smith, L.J.D.; Blowes, D.W.; Ptacek, C.J.; Smith, L.; Sego, D.C. The diavik waste rock project: Persistence of contaminants from blasting agents in waste rock effluent. Applied Geochemistry 2013, 36, 256270.doi: 10.1016/j.apgeochem.2012.04.008. 
71. Yan, Q.; Bi, Y.; Deng, Y.; He, Z.; Wu, L.; Van Nostrand, J.D.; Shi, Z.; Li, J.; Wang, X.; Hu, Z., et al. Impacts of the three gorges dam on microbial structure and potential function. Sci Rep 2015, 5, 8605.doi: 10.1038/srep08605.

72. Weidner, S.; Arnold, W.; Puhler, A. Diversity of uncultured microorganisms associated with the seagrass halophila stipulacea estimated by restriction fragment length polymorphism analysis of pcr-amplified $16 \mathrm{~s}$ rrna genes. Appl Environ Microbiol 1996, 62, 766-771.doi:

73. Morgulis, A.; Coulouris, G.; Raytselis, Y.; Madden, T.L.; Agarwala, R.; Schaffer, A.A. Database indexing for production megablast searches. Bioinformatics 2008, 24, 1757-1764.doi: 10.1093/bioinformatics/btn322.

74. Saitou, N.; Nei, M. The neighbor-joining method: A new method for reconstructing phylogenetic trees. Mol Biol Evol 1987, 4, 406-425.doi: 10.1093/oxfordjournals.molbev.a040454.

75. Keshri, J.; Mishra, A.; Jha, B. Microbial population index and community structure in saline-alkaline soil using gene targeted metagenomics. Microbiol Res 2013, 168, 165-173.doi: 10.1016/j.micres.2012.09.005.

76. Shannon, C.E. A mathematical theory of communication. Bell System Technical Journal 1948, 27, 379-423.doi: 10.1002/j.1538-7305.1948.tb01338.x.

77. Simpson, E.H. Measurement of diversity. Nature 1949, 163, 688-688.doi: 10.1038/163688a0. 